\title{
RBEP
}

\section{Escolarização do corpo e controle de si na revista Estudos Educacionais}

Fernanda Vicente de Azevedo

Ticiane Bombassaro

Alexandre Fernandez Vaz

\section{Resumo}

A revista Estudos Educacionais, publicada entre 1941 e 1946, por alunos do Curso Normal do Instituto de Educação de Florianópolis, foi analisada considerando a configuração no interior da qual a escola catarinense se colocava na primeira metade do século 20: inserção escolanovista e correspondente criação de um sistema de ensino que respondesse ao impulso modernizador. Deste fazia parte a sujeição do corpo ao desenvolvimento de um aparato psíquico forte e regulado. O objetivo de intervir nos corpos infantis aparece no periódico em três eixos: a) as ciências auxiliares (Psicologia, Sociologia e Biologia); b) o valor moral do esporte; e c) a nacionalização do ensino. Tais eixos foram analisados como resultantes do processo de constituição do Estado moderno que imputou à intervenção nos corpos importante papel no controle das paixões e na edificação de um sujeito adequado à vida industrial.

Palavras-chave: corpo; Escola Nova; formação de professores. 


\section{Abstract \\ Body schooling and self control in the publication Estudos Educacionais}

This work analyzes the periodic publication Estudos Educacionais, published between 1941 and 1946 by students of the Curso Normal of Florianopolis Educational Institute. The sources were analyzed taking into account the configuration in which Santa Catarina schools were inserted in the first half of the $20^{\text {th }}$ century: escolanovista insertion and the creation of an educational system in reply to a modernizing impulse. It includes the body subjection to the development of a strong psycho apparatus. The infants' body intervention goal appears in three ways: a) the auxiliary sciences (Psychology, Sociology and Biology); b) the sports moral value; $c$ ) the nationalization of education. These three ways were analyzed as result of the modern State constitution that gave to the body intervention an important role concerning the passion control and the edification of a subject to the industrial life.

Keywords: body; Escola Nova; teachers; education.

O conjunto de práticas institucionais de educação do corpo que oferecem contorno, ao longo dos dois últimos séculos, à formação de crianças e jovens tem sido tema frequentemente pesquisado no campo da História da Educação. As décadas de 1930 e 1940 são, assim como as anteriores, mas com especificidades, representativas de um interesse pela escolarização dos corpos, demonstrado na preconização de normas higienizadoras que ajudaram na pretensão de se construir modelos de homem e mulher adequados aos processos de modernização.

Esse movimento, atravessado pela atenção dedicada aos corpos infantis, esteve ligado, com frequência, à teoria pedagógica em voga no início do século, que se disseminou por meio de reformas educacionais e reformulações curriculares. No caso de Santa Catarina, isso não foi muito diferente. Aquela que ficou conhecida como a filosofia da Escola Nova chegou nesse Estado de forma adaptada às necessidades e às possibilidades político-econômicas locais, ainda que reiterada nos anseios de superar uma educação que não era eficaz para os fins sociais a que se propunha no regime da época (Bombassaro, 2006). Os intelectuais catarinenses porta-vozes da reforma educacional buscaram demarcar seus discursos pela substituição do que se supunha ser uma educação tradicional por uma "nova escola", moderna e renovada, científica e racional, propagadora dos "Imperativos Nacionais" (Pécaut, 
1990) com vistas à edificação de uma cultura genuinamente brasileira antes nunca promovida.

A modernização da escola em Santa Catarina deu atenção à introdução de princípios científicos nos currículos dos cursos de formação de professores, especialmente à instrumentalização técnica para a elaboração de práticas didáticas de intervenção nos comportamentos infantis. $\mathrm{Na}$ expectativa de organizar a população nas escolas, os educadores que se comprometeram com esse projeto pretendiam moldar a instituição na direção de um futuro que exigiria árduo esforço ideologizador (Herschmann; Pereira, 1994). Para tanto, esse movimento precisava ser sustentado em ciências capazes de interpretar os fenômenos sociais e o comportamento individual/infantil. A escola passou a assumir, cada vez mais, uma função disciplinar, tendo sido outorgada às chamadas "ciências fonte da educação" - Sociologia, Psicologia e Biologia - a possibilidade de fornecer instrumentos mais eficientes de ingerência na estrutura somática dos indivíduos escolares. Essa atualização da escola, em geral, e dos métodos e fundamentos da prática pedagógica, em particular, acompanhava o ritmo de crescimento urbano animador vivido pelo País a partir do segundo quartel do século 20.

Uma estrutura econômica baseada em modelos industriais passava a demandar artefatos de controle e contenção das emoções comuns às redes de convívio social, estreitando as conexões entre as funções da escola e os objetivos do Estado. No esforço pedagógico de construção do homem novo que o Brasil necessitava, começava a se materializar a pretensão de edificar um corpo forte e sadio, oferecendo à escola a tarefa da modelação de condutas. No Brasil, os discursos pedagógicos do início do século afirmavam que esse escopo seria atendido por professores instruídos para aplicação de uma pedagogia científica forjada no interior das Escolas Normais, contando com conhecimentos que iam desde a Puericultura até métodos de correção dos corpos e de intervenção na estrutura da personalidade dos escolares.

Fazendo um recorte específico na atenção destinada aos corpos infantis nessa "nova pedagogia" que emergia, o presente trabalho concentra-se na análise de um periódico destinado a veicular ensinamentos aos professores em formação no Estado de Santa Catarina. A revista Estudos Educacionais foi publicada pelos alunos do Curso Normal do Instituto de Educação de Florianópolis, em seis números, entre os anos de 1941 e 1946, reunindo material sobre as aulas ministradas na instituição, traduções de palestras e outras instruções úteis à futura prática dos professores das escolas primárias e secundárias. Os artigos nela publicados resultavam das discussões elaboradas no interior do curso de formação de professores que, com frequência, contava com a participação de eminentes intelectuais da modernização educacional do Estado e do País, proferindo discursos e comunicando as deliberações formais para o campo, fazendo circular grande parte das ideias que embasavam as orientações emitidas pelo Departamento de Educação, órgão máximo de regulamentação 
${ }^{1}$ No ano de 1935, existiam em Santa Catarina duas Escolas Normais Secundárias oficiais, transformadas em Instituto de Educação, uma em Florianópolis e outra em Lages, e outras quatro particulares equiparadas às oficiais, a primeira em Florianópolis, anexa ao Colégio Coração de Jesus, a segunda em Porto União, anexa ao Colégio Santos Anjos, a terceira em Caçador, anexa ao Colégio Aurora, e a quarta em Canoinhas, anexa ao Colégio Coração de Jesus.

${ }^{2}$ João Roberto Moreira era um importante intelectual e professor do Instituto de Educação do Estado e defendia a igualdade de importância entre as disciplinas de Sociologia e Psicologia na constituição da cientificidade do campo educacional. educacional. O Curso Normal, ao qual estava vinculado o Instituto de Educação de Florianópolis, era um dos mais importantes cursos de formação de professores de Santa Catarina ${ }^{1}$ e o único de caráter público na capital.

A escolha por estudar esse periódico deve-se em grande parte ao fato de ele ser um veículo que comunica importantes facetas da constituição de uma pedagogia científica no Estado e favorece a apreensão do que Nóvoa (2002, p. 11) chamou de "[...] discursos que articulam práticas e teorias, que se situam no nível macro do sistema, mas, também no plano micro da experiência concreta, que exprimem desejos de futuro ao mesmo tempo em que denunciam situações do presente."

Nota-se no periódico uma grande variedade de colaboradores durante a sua publicação; uns mais constantes, outros tendo assinado apenas um artigo ao longo dos anos. Com exceção apenas das traduções de palestras que apareciam assinadas pelos autores originais da preleção, os signatários são alunos e professores do Curso Normal e, por vezes, o próprio diretor do Instituto de Educação e editor da revista, João Roberto Moreira. ${ }^{2}$

É possível observar na revista o interesse em divulgar atualidades teóricas e metodológicas do campo educacional, articulando-as com questões pertinentes aos desafios políticos e culturais do Estado catarinense. Nesse sentido, verifica-se o crescente interesse pelo corpo nos processos de modernização pedagógica, desde a sexualidade até os esportes, dos hábitos de higiene às feminilidades e masculinidades. Para os fins deste artigo, foram destacados, em especial, três grandes eixos que organizam as discussões a respeito da escolarização dos corpos: a) as ciências auxiliares - a Psicologia, como a disciplina capaz de apontar as conexões entre a maturidade biológica e a adaptação psíquica, a Sociologia, para corrigir as condições ambientais em tempo útil, "se não teremos os retardados mentais, os caracteres violentos, os preguiçosos", e a Biologia, dispositivo efetivo de correção e maleabilidade dos corpos; b) o valor moral do esporte - introduz uma nova forma de compreender os jogos como "um processo sadio para a eugenia da raça e para elevar, o mais alto possível, a moral do povo"; e c) a nacionalização do ensino - a necessidade de construir uma mentalidade nacional e uma conduta ordeira, sobrepondo às etnias estrangeiras uma cultura nacional.

Esses eixos, traçados com a finalidade de expor mais sistematicamente o conteúdo de nossas análises, foram pensados no contexto de criação de uma série de objetivos políticos a serem assumidos pela escola e para os quais a formação docente tornou-se um importante instrumento. Observa-se que uma pedagogia forjada no interior de um currículo de formação de professores no Estado atribuía grande importância às "ciências fontes da educação" e dedicava especial atenção aos corpos dos alunos, em consonância com o sentido civilizador da escola. Ao referir-se aos processos de ensino-aprendizagem, a revista apontava regularmente para a necessidade crescente do domínio de si, para a sujeição do indivíduo ao desenvolvimento de um aparato psíquico forte e regulado, utilizando 
as práticas esportivas para esse fim e instituindo uma estruturação mais frequente do tempo livre das crianças.

\section{Três vértices das preocupações com o ensino moderno: ciência, esporte e assimilação}

Uma das mais expressivas reformas que deram impulso à modernização da formação docente baseada nos moldes racionais e científicos em Santa Catarina foi a chamada "Reforma Trindade" (Santa Catarina, 1935). Além de introduzir uma série de modificações na estrutura de regulação do campo educacional, foram reorganizados também os cursos de formação de professores: as Escolas Normais públicas foram transformadas em Institutos de Educação e as Escolas Normais privadas do Estado ${ }^{3}$ foram obrigadas a equiparar-se a eles. No ano de 1939, os Institutos tiveram sua estrutura reformulada mais uma vez (Santa Catarina, 1939), a qual se manteve até a regulamentação federal para a formação de professores no ano de 1946 (Decreto $\left.n^{\circ} 3.735 / 1946\right)$.

Tal reforma se espelhou em larga medida nas reorganizações antes empreendidas em São Paulo e no Rio de Janeiro por Lourenço Filho e Fernando de Azevedo, expoentes da Escola Nova no País. Santa Catarina criou, a exemplo disso, a sua Escola Normal Superior Vocacional que, como o curso de Aperfeiçoamento Pedagógico de São Paulo, dava ênfase a disciplinas como Psicologia, Sociologia e Higiene e Puericultura. Ao ser extinto em 1939, o Curso Vocacional deu lugar ao Normal de dois anos, que manteve a estrutura curricular ligada ao que se convencionou chamar de "formação pedagógica".

A ênfase em um determinado grupo de disciplinas que visava à fundamentação teórico-científica da formação do professor se evidenciava em sua importância para a construção de uma nova forma de ensinar. Uma expressão disso é o peso que esse conjunto de conhecimentos possuía para a progressão na carreira escolar: do chamado $1^{\circ}$ grupo (Psicologia Educacional, Pedagogia, Biologia Educacional, Sociologia Educacional e História da Educação, Metodologia e Prática do Ensino, Língua e Literatura Vernáculas), seria exigida a obtenção de média mínima 5,0, e o normalista que não a alcançasse estaria sujeito à reprovação, quando seria requerida a assistência a todas as aulas do grupo novamente. A um $2^{\circ}$ grupo de disciplinas, porém, exigia-se média 4,0 e deveria ser repetida apenas aquela para a qual não se houvesse obtido o valor mínimo determinado.

O peso desse conjunto de disciplinas, verificado por essa atribuição distinta de "valores" no currículo, reflete a importância que elas assumiam como fundamentos de uma ação educativa mais científica e racional, livre do "empirismo" que se imputava às pedagogias anteriores. Se a escola fazia parte de um projeto civilizador que sustentava, por meio da ciência e da técnica, a racionalização do trabalho, pode-se admitir que ela se tornava um importante espaço de regulação, homogeneização, disciplinarização, ordenação e higienização de hábitos e comportamentos, assumindo, ainda,

\footnotetext{
${ }^{3}$ Nesse momento, existiam duas Escolas Normais públicas, uma em Florianópolis e outra em Lages, e as Escolas Normais privadas, anexas aos colégios Coração de Jesus (Florianópolis), Santos Anjos (Porto União), Aurora (Caçador) e Coração de Jesus (Canoinhas).
} 
${ }^{4}$ Obras de Durkheim eram frequentemente citadas em circulares e programas de ensino de Sociologia Educacional para os cursos de formação docente no Estado. No ano de 1937, o programa de Sociologia Geral contava com um tópico exclusivo sobre "A obra metodológica de E. Durkheim" (cf. Santa Catarina. Departamento de Educação, 1939). a necessidade de modificar a "natureza" do sujeito pela correta ação educativa. Por isso, tornava-se frequente a exaltação dos conhecimentos basilares da Psicologia, da Biologia e da Sociologia, transformadas em ferramentas para a compreensão do desenvolvimento psíquico, fisiológico e social ao instrumentalizar o professor para a análise e o entendimento das especificidades da progressão dos escolares.

Alguns desses recursos provenientes dos debates em âmbito nacional vinham sendo aplicados no Estado, mas ainda permanecia a necessidade de garantir condições materiais e técnicas para implantar o modelo escolar que em outros países tinha viabilizado a escola de massas. Fatores como a seriação, as classes homogêneas, o ensino simultâneo, a regulamentação e uniformização do tempo escolar, o enquadramento disciplinar e a organização do espaço escolar, aliados a uma nova estruturação do conceito de atividade, surgem como novos guias às práticas escolares modernas.

Nesse contexto, vários artigos publicados na revista Estudos Educacionais enfatizam o uso das disciplinas científicas como elementos de reconfiguração das práticas pedagógicas e do processo ensino-aprendizagem em sentido técnico-racional. Por vezes, as justificativas de novas práticas didáticas passaram a centrar-se numa compreensão de que a escola deveria ser o vetor de transformação social pela indução de novos modelos de comportamento, sociabilidade, higiene e até de uso do tempo livre, buscando concentrar nas mãos dos professores a possibilidade de intervir com eficiência na "natureza" do indivíduo.

Um dos primeiros discursos provenientes do fundamento científico dessas novas concepções sobre o ensino em Santa Catarina se refere ao reconhecimento de que o meio social exerceria sobre a prática educativa e a construção da personalidade dos indivíduos uma influência a ser considerada e analisada pela escola e, em especial, pelo professor, a fim de ser retrabalhada e direcionada em concomitância ao imperativo nacional.

O pressuposto da "influência que o meio exerce sobre o indivíduo" é herdeiro da Sociologia Positivista, fortemente alicerçado nas teses de Emile Durkheim ${ }^{4}$ e justificado pela busca de uma educação adaptada às exigências de seu tempo, considerando "o indivíduo não apenas como um componente da sociedade, mas sim como uma creação, uma resultante da sociedade" (Bauer, Reis, 1941, p. 14).

Observe-se um exemplo em mais um trecho do texto de duas alunas do Curso Normal no ano de 1943:

É a sociedade exclusivamente que cria nos homens os sentimentos familiares, religiosos, estéticos, enfim, todas as tendências que não são como a sede, a fome, a satisfação sexual, ligados diretamente a excitações orgânicas imediatas. Ela age, entretanto, mesmo sobre estas, transforma-as e socializa-as. Assim o pudor, a fidelidade às promessas, o sentimento do dever e de honra, o respeito a propriedade são produções meramente sociais... A cada passo, vamos vendo o indivíduo e a sociedade se condicionarem mutuamente, de modo que é legítimo dizer-se que o primeiro faz refletir-se naquela a marca de sua personalidade, ao passo que a sociedade penetra em nossa vida individual, condicionando, ora de modo mais intenso, ora menos, a totalidade de nosso comportamento. (Bauer, Reis, 1944, p. 14). 
As afirmações acima remetem a Durkheim (1978, p. 57), especialmente no sentido de que a moral estaria estreitamente relacionada com o tipo de sociedade em que o indivíduo se desenvolve, pois é ela que "nos liberta de nós mesmos" e nos ensina "a dominar as nossas paixões, os nossos instintos, a fazer-lhe a própria lei, privarmo-nos, sacrificarmo-nos." Dominar a natureza pode ser considerado o maior desiderato da modernidade, e esse discurso sociológico que profetiza a supremacia da sociedade sobre o indivíduo torna o corpo irrenunciável objeto de domesticação, "escarnecido e repelido como algo inferior e escravizado, e, ao mesmo tempo, desejado como o proibido, reificado, alienado" (Horkheimer, Adorno, 1985, p. 217).

Ao incorporar na escola o discurso de uma necessária intervenção nos modos de viver como influência deliberadamente exercida sobre o indivíduo, condicionando o comportamento, a Sociologia a que as alunas se remetem nos textos da revista é aquela destinada ao "tipo coletivo" ou "tipo genérico de homem" que Durkheim justifica pela importância das necessidades sociais se sobreporem às individuais:

O homem que a educação deve realizar, em cada um de nós, não é o homem que a natureza fez, mas o homem que a sociedade quer que ele seja; e ela o quer conforme o reclame a sua economia interna, o seu equilíbrio. [...] Será preciso que, pelos meios mais rápidos, ela acrescente ao ser egoísta e associal que acaba de nascer uma natureza capaz de aceitar a vida moral e social. Eis aí a obra da educação. (Durkheim, 1978, p. 81-82).

Inserir um conjunto de práticas científicas nas instruções da Escola Normal diz respeito à frequente problemática de intervenção nos corpos e espíritos das crianças com fins de edificar o cidadão moderno. Esse processo remete à maleabilidade da constituição física e psíquica do Homem e às modelações ocorridas no curso da história e diretamente relacionadas às cadeias de interdependência que se estabelecem no interior de uma sociedade. Tal fato é bem apontado por Norbert Elias (1993), quando afirma que a plasticidade humana não se limita ao que em geral diferenciamos como o "psicológico" e o "fisiológico". Comumente, os textos se referem indissociadamente ao "psíquico" e ao "orgânico", a fim de que os professores evitassem o dualismo ao trabalhar essas dimensões no indivíduo escolar.

Portanto, se a primeira maleabilidade das crianças residia na influência social recebida desde cedo, e bem alertada pela Sociologia Educacional, o corpo também deveria ser reorientado para os fins sociais desejáveis, já que a sua educação visava "tornar o ser humano mais resistente, sob o ponto de vista físico e intelectual" (Samy, 1946, p. 33).

A ênfase que recai sobre os corpos na Escola Normal nesse período tem ainda uma função higiênica. Na assistência de aulas de Biologia e práticas no Centro de Saúde local, os alunos do Curso Normal aprendiam o que se supunha que fossem experiências saudáveis para a vida pessoal e também noções de higienização a serem ensinadas ao seu futuro grupo de crianças. 
Corrigir o corpo disforme era uma ambição declarada da escola. Para tanto, noções ortopédicas eram ministradas nas aulas de Biologia no Curso Normal, alertando que os desvios da coluna vertebral provocados por estudos em posições impróprias eram os principais vilões a serem combatidos. Se não houvesse uma profilaxia das deformidades, outras irregularidades no corpo do estudante seriam provocadas, como disfunção visual, problemas de pulmão e coração: "as anomalias da coluna vertebral devem ser evitadas, tanto quanto possível, no escolar, porque, além dos defeitos físicos que elas podem produzir, também há outros que são resultados dessas anomalias, ou melhor, que ocorrem por conta dessas anomalias" (Faísca, 1942, p. 61).

Tal alerta é comum no sentido de que os discursos pedagógicos proferiam que a deformidade corporal poderia ser causa, e por vezes índice, de uma condição intelectual que precisava, igualmente, ser saneada, corrigida. Há, para tanto, no artigo supracitado uma lista de deformidades que seriam características da "vida escolar" e outras apontadas como resultado de más influências do meio (no caso de obesidade ou de posturas causadas pelo hábito de "transportar pesos sobre a cabeça"). Em relação à escola, os vícios posturais deveriam ser evitados por um mobiliário adequado e pela censura frequente do professor. Para tanto, afirmava-se que:

Fora de dúvida está que a educação racional do corpo repercute, benèficamente (sic), sôbre o trabalho intelectual, tornando o cérebro mais disposto, mais receptivo, e permitindo-lhe mais ràpidamente (sic) transformar em ciência prática as noções recebidas. Ela, como nos demonstra a moderna fisiologia, atua sôbre os centros nervosos e sôbre o cérebro e, por conseqüência, sôbre a inteligência. (Samy, 1946, p. 35).

Desde os testes de inteligência propostos por Lourenço Filho até os mais recentes gabinetes biométricos, ambos instalados em Santa Catarina em meados dos anos 1930, imputar à Pedagogia o caráter científico, novo, moderno e experimental passava pelo alinhamento de corpos e condutas a uma forma padrão de normalidade. As anomalias e degenerescências corporais precisavam ser identificadas e, quando possível, saneadas, passando a ser responsabilidade de um professor bem instruído o combate da proliferação de doenças e anomalias no âmbito escolar. Esse discurso científico sobre as relações entre aprendizagem e saúde demonstra a assunção de uma Pedagogia tomada como ciência de mensuração e, eminentemente, ortopédica e higiênica.

Uma escola, que deveria ser vigilante na promoção de um corpo apto aos valores modernos, enfatizava a necessidade de sanear o corpo e dominar as paixões, fazendo com que as noções gerais sobre a estrutura e o funcionamento do corpo humano servissem para fundamentar a correção também dos comportamentos que não respondessem às expectativas escolares: "muitos alunos considerados preguiçosos ou relaxados não são mais do que doentes glandulares. Necessário se torna termos noções gerais de endocrinologia para que possamos formular as regras pedagógicas modernas, pois somos, em parte, resultado das glândulas endócrinas" (Fortes, 1941, p. 62). 
Para tornar a escola eficiente nesse propósito, uma das modificações curriculares aclamadas pelos discursos publicados no periódico dizia da definição de um programa de educação física centrado em exercícios de ginástica e na prática de esportes. Se a primeira estava destinada a desenvolver grupos musculares por exercícios de repetição, os últimos foram assumidos como uma técnica de incorporação de regras e de aprimoramento físico e psíquico na constituição de um homem sadio e livre de "taras". O que se esperava era que as experiências com o esporte reforçassem um caráter íntegro, disposto e contido, fazendo disso um ensaio para o aprendizado da convivência social.

A educação física nas escolas, como era propagandeada na revista, deveria ser adotada como uma metodologia para ensinar a viver, promovendo bons hábitos pelo esporte e edificando a personalidade do gentleman. Honestidade, bondade e senso de justiça eram as habilidades que poderiam ser estimuladas pela prática disciplinada de educação física, eliminando riscos de explosões emocionais.

Mais do que averiguar as possibilidades da introdução da "cultura física" para fins sanitários, o artigo de João Aldo Nunes, aluno do $1^{\circ}$ ano do Curso Normal, publicado no quinto número da revista, promulgava a utilidade dos esportes como complemento da "educação integral" e da constituição do homem moralmente sadio. O normalista identifica no histórico da introdução dos esportes anglo-saxônicos no Brasil uma tendência ao desequilíbrio das forças demarcado por uma dedicação extrema por parte dos jovens às práticas esportivas em detrimento das atividades intelectuais. A condição de extrema proximidade da natureza pela prática de exercícios era criticada com veemência, pois "ser simplesmente atleta é quase ser selvagem." ${ }^{5} \mathrm{O}$ esporte gratificaria as demandas instintuais (pulsionais) ao criar um espaço para dar vazão aos afetos mais incontroláveis e inadmissíveis no mundo social. Ao se sujeitar à expressão dos impulsos mais elementares, o indivíduo estaria à mercê do descontrole, de sua própria natureza, que, ao contrário, deveria ser dominada e controlada pela incorporação dos códigos de civilidade. E eis aí a ambiguidade pedagógica do esporte a ser explorada pelo normalista: sendo aquele o espaço por excelência do descontrole, seria por ele mesmo que aconteceria o treinamento das habilidades sociais requeridas. Afirma o autor:

O esporte pode desenvolver o espírito de solidariedade humana, criando, assim, laços de verdadeira amizade entre as nações; nos indivíduos pode criar o espírito de cooperação, a rivalidade, que poderá, muitas vêzes, produzir bons frutos. Coragem, honestidade, desinteresse, lealdade, veracidade, modestia e integridade são algumas qualidades pessoais que podem resultar de um organizado programa de esportes e jogos. [...] O esporte deve ser praticado não só para obter-se harmonia de formas, aprimorar e conservar as linhas anatômicas não quebradas pela influência do meio, em que, às vezes, o homem deve lutar com uma natureza hostil, que pode deformar a perfeição dessas linhas. O esporte deve ser praticado a fim de preparar os indivíduos para enfrentarem as lutas diárias. (Nunes, 1943, p. 66).
5 A citação é feita por Nunes (1943), que não a referencia. Indica como inspiração, no entanto, o filósofo Platão. 
O acento na cooperação pode estar relacionado a dois aspectos, no caso catarinense: a criação de noções de hierarquia, obediência e colaboração, úteis ao trabalho em geral, mas também a necessária supressão de rivalidades sociais e consequente integração de etnias, problema eminente no Estado ressaltado como um dilema a ser enfrentado pela escola:

Compreendido que seria a escola o único meio de conseguir a unidade nacional, ele começou a sua reação tomando para si a direção de todas as escolas, fechando as estrangeiras, eliminando professores que não admitissem todas as disciplinas na língua pátria, abrindo no local escolas brasileiras, dirigidas por professores brasileiros. (Bastide, 1943, p. 31).

O que a campanha de assimilação coloca em jogo, mais uma vez, é a capacidade de a escola exercer uma influência na edificação de indivíduos conformados ao novo contexto nacional. A crítica à escola de outrora teria sido, segundo o discurso da revista, incorporada para demonstrar a sua ineficiência na conquista do objetivo de construir uma cultura única e integrar os imigrantes. O trecho abaixo é parte de uma entrevista concedida pelo francês Roger Bastide, professor de Sociologia na Universidade de São Paulo, quando solicitado a analisar os "quistos raciais" em Santa Catarina:

\begin{abstract}
As escolas [dos imigrantes] não visavam educar para a sociedade, ou para formar um indivíduo cidadão, com orgulho e perfeito conhecimento de sua pátria; tinham por finalidade exclusiva formar mentalidades religiosas ou transmitir conhecimento. Esse processo, porém, em vez de unir os filhos de uma pátria, separavam-nos, havendo países com escolas aperfeiçoadas para as determinadas classes sociais, como se viam na França, sendo muitas vezes vedado ao indivíduo frequentar a classe superior. (Bastide, 1943, p. 32).
\end{abstract}

Ao apontar falhas na equidade do sistema educacional de outros países, inclusive do seu próprio, Bastide buscava uma justificativa para a imposição da frequência a escolas brasileiras aos imigrantes, obrigando a convivência entre aqueles que o intelectual considerava etnicamente diferentes. Ficava claro, naquele momento, que pelo mero esforço de doutrinação não seria possível incutir os hábitos desejados nos escolares que não estivessem no sistema público. Daí a obrigatoriedade de o ensino ser a oportunidade de homogeneizar e higienizar hábitos e atitudes em massa, instalando na vida privada uma ingerência que teria como ponto de partida a escola.

Isso se tornava necessário pela autonomia desenvolvida pelas comunidades estrangeiras, que haviam criado não somente escolas vinculadas às suas tradições culturais, mas também cultivavam hábitos, como a frequência a associações desportivas, com caráter de exaltação política muito atrelada às origens estrangeiras. O projeto de assimilação passava, então, pela extinção dos espaços de confraternização dos imigrantes e sua substituição por ambientes que favorecessem o controle e a normatização dos comportamentos, dos sentimentos e das condutas, afinando-os às necessidades nacionais. 


\section{Algumas considerações}

A tendência geral no campo educacional dos anos de 1930, de valorização da formação docente como eixo pelo qual passariam grande parte das mudanças na estrutura da escola, por meio de uma didática científica, faz eco no periódico Estudos Educacionais, em Santa Catarina, na década seguinte.

Ao contar com contribuições de diversos intelectuais de renome (Roger Bastide, Lourenço Filho, Fernando de Azevedo, etc.), a revista buscava atualizar os professores e fazer circular uma série de ensinamentos teórico-práticos que se suponha que modernizariam as ações educativas nas escolas primárias e secundárias. Agir segundo as "modernas teses do ensino", em geral sob influência da Sociologia Francesa e da Psicologia Experimental, aproximava os professores da fundamentação científica desejada para a construção de novos rumos sociais.

O que interessa ressaltar, na análise dos três eixos que identificamos nos artigos analisados, é a ênfase na possibilidade de construir e direcionar impulsos e afetos por meio de uma ação educativa adequada. Em especial, observa-se que o corpo ocupa um lugar de destaque nas teses de modernização do ensino ao tornar-se objeto no qual se identifica as maiores mudanças de tendências, por meio do domínio da sua "natureza".

Reorientar as tendências passava diretamente pela correção dos corpos doentios, enfatizando a necessidade de lições de higiene, mas também de doutrinação no sentido estrito de desenvolver aptidões que se manifestassem também fora das instituições escolares e se irradiassem para as comunidades. Isso só seria possível pela investigação psicológica nos indivíduos, conforme a nova ciência, a Psicologia, que instrumentalizaria as formas didáticas dos processos de ensino. A principal delas consistia naquilo que já preconizava Emile Durkheim (1978, p. 86), a capacidade de submeter a si e ao outro a severidade continuada:

[...] não é que não existam em nós capacidades muito gerais, sem as quais esse ideal seria evidentemente irrealizável. Existem, sem dúvida. Se o homem pode aprender a sacrificar-se é porque não é incapaz de sacrifício; se pode submeter-se à disciplina da ciência é porque não é absolutamente incapaz disso.

Se havia uma potência inata, que poderia ser alvo de reformulação em novos códigos e princípios e tornar-se algo distinto dessa natureza, esta passava a ser a função da escola e demandava conhecimento das ciências emergentes e estratégias didáticas inteiramente novas. 


\section{Referências bibliográficas}

BASTIDE, R. Educação dos educadores. Estudos Educacionais, Florianópolis, SC, n. 4, jun. 1943.

BAUER, A.; REIS, E. Reações infantis às situações sociais. Estudos Educacionais, Florianópolis, SC, n. 2, nov. 1941.

BOMBASSARO, T. Semanas educacionais: a arquitetura do poder sob a celebração da didática. 128 f. Dissertação (Mestrado em Educação) Universidade Federal de Santa Catarina, Florianópolis, 2006.

CARVALHO, M. M. C. de. Modernidade pedagógica e modelos de formação docente. São Paulo em Perspectiva, v. 14, n. 1, p. 111-120, mar. 2000.

DURKHEIM, E. Educação e Sociologia. São Paulo: Companhia Melhoramentos, 1978.

ELIAS, Norbert. O processo civilizador: formação do Estado e civilização. Rio de Janeiro: Jorge Zahar, 1993. v. 2.

FAÍSCA, A. Os desvios na coluna vertebral dos escolares. Estudos Educacionais, Florianópolis, SC, n. 3, nov. 1942.

FORTES, R. J. Glândulas endócrinas. Estudos Educacionais, Florianópolis, SC, n. 2, nov. 1941.

HERSCHMANN, M. M.; PEREIRA, C. A. M. A invenção do Brasil moderno: Medicina, Educação e Engenharia nos anos 20-30. Rio de Janeiro: Rocco, 1994.

HORKHEIMER, M.; ADORNO, T. W. Dialética do esclarecimento: fragmentos filosóficos. Rio de Janeiro: Jorge Zahar, 1985.

NÓVOA, António. A imprensa de Educação e Ensino: concepção e organização do repertório português. In: CATANI, D. B.; BASTOS, M. H. C. (Orgs.). Educação em Revista: a imprensa periódica e a História da Educação, São Paulo: Escrituras, 2002.

NUNES, A. J. O valor moral e físico do esporte. Estudos Educacionais, Florianópolis, SC, n. 5, dez. 1943.

PÉCAUT, Daniel. Os intelectuais e a política no Brasil: entre o povo e a nação. São Paulo: Ática, 1990.

SAMY, Prof. A Educação física, base da intelectual. Estudos Educacionais, Florianópolis, SC, n. 6, mar. 1946. 
SANTA CATARINA. Decreto n. 3735, de 17 de dezembro de 1946.

Regulamento para os estabelecimentos de ensino primário no Estado de Santa Catarina. Florianópolis, Imprensa Oficial, 1946.

. Decreto-lei n. 713, de 8 de janeiro de 1935. Diário Oficial do

Estado de Santa Catarina, Florianópolis, 1935.

. Decreto-lei n. 306, de 2 de março de 1939. In: COLEÇÃO de

Decretos-Leis de 1939. Florianópolis, 1939.

SANTA CATARINA. Departamento de Educação. Programas Provisórios aprovados pela Superintendência Geral do Ensino. Instituto de

Educação de Florianópolis. Curso Normal - regulamenta os conteúdos a serem ministrados na disciplina de Sociologia. Diário Oficial do Estado de Santa Catarina, Florianópolis, v. 6, n. 1463, 5 abr. 1939.

Fernanda Vicente de Azevedo, mestranda em Educação pela Universidade Federal de Santa Catarina (UFSC), é membro do Núcleo de Estudos e Pesquisas Educação e Sociedade Contemporânea (CED/UFSC/ CNPq).

fernandadeazevedo@hotmail.com

Ticiane Bombassaro, doutora em Educação pela Universidade Federal de Santa Catarina (UFSC), é pesquisadora do Instituto Nacional de Estudos e Pesquisas Educacionais Anísio Teixeira (Inep) e membro do Núcleo de Estudos e Pesquisas Educação e Sociedade Contemporânea (CED/UFSC/ CNPq).

ticib@bol.com.br

Alexandre Fernandez Vaz, doutor pela Leibniz Universität de Hannover, é professor dos Programas de Pós-Graduação em Educação e Interdisciplinar em Ciências Humanas da Universidade Federal de Santa Catarina (UFSC) e coordenador do Núcleo de Estudos e Pesquisas Educação e Sociedade Contemporânea (CED/UFSC/CNPq).

alexfvaz@uol.com.br

Recebido em 2 de fevereiro de 2011.

Aprovado em 25 de abril de 2011. 


\section{Fontes documentais}

BASTIDE, R. Educação dos educadores. Estudos Educacionais, Florianópolis, SC, n. 4, jun. 1943.

BAUER, A.; REIS, E. Reações infantis às situações sociais. Estudos Educacionais, Florianópolis, SC, n. 2, nov. 1941.

FAÍSCA, A. Os desvios na coluna vertebral dos escolares. Estudos Educacionais, Florianópolis, SC, n. 3, nov. 1942.

FORTES, R.J. Glândulas endócrinas. Estudos Educacionais, Florianópolis, SC, n. 2, nov. 1941.

NUNES, A. J. O valor moral e físico do esporte. Estudos Educacionais, Florianópolis, SC, n. 5, dez. 1943.

SAMY, Prof. A Educação física, base da intelectual. Estudos Educacionais, Florianópolis, SC, n. 6, mar. 1946.

SANTA CATARINA. Decreto-lei n. 713, de 8 de janeiro de 1935. Diário Oficial do Estado de Santa Catarina, Florianópolis, 1935.

. Decreto-lei n. 306, de 2 de março de 1939. In: COLEÇÃO de Decretos-Leis de 1939. Florianópolis, 1939.

. Decreto n. 3735, de 17 de dezembro de 1946. Regulamento para os estabelecimentos de ensino primário no Estado de Santa Catarina. Florianópolis, Imprensa Oficial, 1946.

SANTA CATARINA. Departamento de Educação. Programas Provisórios aprovados pela Superintendência Geral do Ensino. Instituto de Educação de Florianópolis. Curso Normal - regulamenta os conteúdos a serem ministrados na disciplina de Sociologia. Diário Oficial do Estado de Santa Catarina, Florianópolis, v. 6, nº 1463, 5 abr. 1939. 